\title{
EXPLORING LEADERSHIP INFLUENCE WITHIN DATA-INFORMED DECISION-MAKING PRACTICES IN AUSTRALIAN INDEPENDENT SCHOOLS
}

\author{
VENESSER FERNANDES
}

\begin{abstract}
There is increasingly strong pressure on schools to use data within their decision-making processes; the pressure comes not just from high-stakes testing but also from the subsequent comparative analysis conducted in the international, national, state, and local jurisdictions that represent the educational systems responsible for ensuring that students continue to receive quality education (Harris \& Jones, 2017). There is paucity in empirical research within Australia on the practice of data use within schools; research is lacking on data interactions among school leaders in their workplace settings (Coburn \& Turner, 2012). This study contributes toward this identified gap in Australian research literature on the practice of data-informed decision making (DIDM) in schools. Using a case-study approach at two K-12 independent schools in Victoria, Australia, the study sought to understand the "bow" and "why" of DIDM systems that are currently in use within Australian independent schools in order to better understand what data-informed school improvement processes are being used in practice in this sector of Australian schooling. Based on the findings, we offer recommendations for developing improved system capabilities that make schools data literate and numerate and identify the important transformational role that senior and middle-level school leaders play in building up data-informed collaborative school cultures within their schools.
\end{abstract}

\section{Keywords}

school leaders, data-informed decision making, collaboration, continuous school improvement, organizational trust 


\section{Introduction}

The last decade has seen increasing pressure on schools to use data within their decision-making processes. This pressure comes from high-stakes testing and from subsequent comparative analyses conducted at international, national, state, and local levels of jurisdiction. These jurisdictions represent the educational systems responsible for ensuring students are receiving quality education (Harris \& Jones, 2017). Similar to the United States, in Australia "the use of data in educational decision-making is expected to span all layers of the education system-from the federal to the state, region, school and classroom levels" (Means et al., 2009, p. 7). Some studies have looked at the growing emphasis given to high-stakes testing (Harris \& Hargreaves, 2015) as one of the reasons why more data use has been seen (Smeed et al., 2011). Research indicates that a key strategy directly contributing toward school improvement is effective data use within their decision-making processes (Argyris \& Schön, 1996; Brown, 2015; Coburn \& Turner, 2012; Earl \& Katz, 2006; Earl \& Timperley, 2009; Fernandes, 2016, 2019, 2021; Phillips, 2003; Robinson \& Walker, 1999; Schildkamp et al., 2017; Schildkamp et al., 2019; Timperley, 2005a, 2005b, 2006; Vanlommel et al., 2018).

As Australian independent schools ( $\mathrm{N}=1169$ schools) are autonomous, their accountability frameworks and continuous school improvement processes vary, unlike the public or Catholic school sectors. Freedom in autonomous decision making is considered to be fundamental to independent schooling in Australia. This autonomy enables them to work in partnership with their school community to develop unique and custom-built schools that meet the specific needs of their students (ISCA, 2018). Independent schools are also compliant with external accountabilities set by state and federal education regulations and standards.

Australian independent schools have always been self-managing school systems. Within their regular systems of educational practice, reasonable levels of data literacy and data numeracy are expected to be used when making informed educational decisions. This role of data use in educational decision making has gained traction in recent years with the accessibility of information and mandated transparency of school data in Australia. As reported by the Independent Schools Queensland (2018):

There is now more publicly available information on schools than ever before, particularly in the case of independent schools. This means their level of accountability to parents, Governments and the wider community has increased significantly. Transparency in terms of school outcomes is now firmly embedded into the education system... An important aspect of school transparency and accountability is the need for Governments to be assured 
their increasing expenditure on schooling is being used appropriately and is achieving outcome levels that are in line with national and state expectations. Governments collectively spend nearly $\$ 60$ billion annually on schools; it is not unreasonable on behalf of taxpayers, that they should have data to indicate the effectiveness of such expenditure (pp. 1-2).

School data includes any relevant information about school stakeholders derived from qualitative and quantitative sources internal or external to the school representing a certain aspect of school improvement being studied. The researcher recorded 32 different kinds of datasets commonly found in schools in Victoria, Australia (Fernandes, 2019). More broadly, these datasets could be divided into four groups: demographic data, student learning data, perception data, and school processes data (Bernhardt, 2003), all providing insights into various aspects of Australian schools.

This paper discusses how two Australian K-12 independent schools make use of data-informed decision-making (DIDM) approaches to inform their school improvement processes. Second, it discusses how senior and middlelevel leaders at these schools have engaged in understanding their data, made data-informed decisions, and moved their continuous school improvement processes forward. Third, this paper focuses on investigating how the practice of a DIDM approach was developed at these case-study schools. Two themes emerged from the findings: the level of dynamic over passive enhancement of school capabilities and the level of active versus passive leadership involvement in DIDM.

\section{Literature Review}

An international body of literature supports DIDM and its role in equipping school leaders and teachers in improving educational outcomes within their schools (Datnow \& Hubbard, 2015, 2016; Datnow \& Park, 2018; Earl \& Katz, 2006; Fernandes, 2019, 2021; Lai et al., 2014; Lai \& Schildkamp, 2013; Mandinach et al., 2015; Mandinach \& Gummer, 2013; Poortman \& Schildkamp, 2016; Schildkamp \& Kuiper, 2010; Thoonen et al., 2011; Van Gasse et al., 2016; Vanhoof et al., 2012; Vanlommel et al., 2016; Wayman et al., 2012; Wayman \& Jimmerson, 2014).

The divide between expectations of data-informed school improvement practices and the actual realities of school improvement practice (Honig \& Coburn, 2008; Spillane, 2012) are significant in Australia. As Schildkamp et al. (2017) noted, "although data-based decision-making can lead to improved student achievement, data are often not used effectively in schools" (p. 242). A better understanding of DIDM would help schools in making better use 
of their data for school improvement (Fernandes \& Henderson, 2020). A data-informed school has: shared leadership and responsibility; a mission identifying its goal and purpose as a learning community; a cadre of leaders, learners, inquirers, and worriers; identification of critical issues, essential questions, and focus problems; planning strategies to collect data and information; processes for implementation; resources and time to engage and complete tasks; feedback and recycling of experiences; reporting and sharing data and experience; and repetition and continuation of the process of data collection, use, and change (Hansen et al., 2003). Coburn and Turner (2012) identified a definite lack of empirical research on the practice of data use within schools:

....in spite of all of the policy and reform activity focused on data use in education, empirical research on data use continues to be weak. In particular, we still have shockingly little research on what happens when individuals interact with data in their workplace settings (p. 99).

Addressing this gap in Australian research literature on DIDM, this paper seeks to understand the "how" and the "why" of DIDM systems in practice within two independent schools in Victoria, Australia. "Practice" within this context is defined as "the coordinated activities of individuals and groups in doing their 'real work' as informed by particular organizational or group contexts" (Cook \& Brown, 1999, pp. 386-387). Schools that use data effectively practice data use regularly.

Park and Datnow (2009) suggested that data-driven decision-making is co-constructed by multiple actors at three different levels of interaction. First, leaders play a pivotal role at all levels in co-constructing the vision and implementation of data-driven decision-making through their framing of the purpose of data use and the creation of an ethos of learning and continuous improvement rather than one of blame. Next, leaders distribute decisionmaking authority, empowering different staff members to utilize their level of expertise. Third, the school system directs their resources on building staff capacity by modelling and knowledge brokering amongst their staff. Schildkamp et al. (2019) discussed how leadership within schools can enable or hinder the use of data within respective units or teams using data for informed decision-making. Schildkamp et al. (2019) observed that a transformational leadership approach leads to better data use which subsequently could lead to successful changes in teaching practices within schools. According to Schildkamp et al. (2019), this is done in five ways and through the use of communities of practice known as data teams. First, school leaders establish a vision, norms, and goals. Second, they provide individualized emotional support to staff. Third, they promote intellectual stimulation such 
as sharing knowledge and providing autonomy. Fourth, they create safe climates for data use focused on improvement over accountability. Lastly, they use networking to connect different parts of the school organization by creating an internal data use network with the school.

\section{Research Design and Methods}

This study used an explorative qualitative case-study design. The study investigated emerging themes around school leadership by studying the use of an evidence-based organizational change and development approach making use of DIDM within their continuous school improvement processes.

The participants of this study included the senior and middle-level school leaders at two K-12 independent schools in Victoria, Australia. Data collection methods included semi-structured interviews with participating school leaders $(\mathrm{N}=25)$, field observations of DIDM activities $(\mathrm{N}=18)$, and institutional document analysis $(\mathrm{N}=28)$. The researcher used a reflective journal recording four types of reflective notes for both research sites. Data collection took place over 2017-2018. Lincoln and Guba (1985) identified four characteristics for assessing trustworthiness in qualitative research: credibility, dependability, conformability, and transferability. Member-checking of interview transcripts was employed, in which the interview transcripts were checked by the participants for clarity of meaning and accuracy and to build credibility of the datasets. Dependability was ensured by triangulating the datasets. Conformability was established through thematic analysis by comparing approaches taken by participants in their use of DIDM within their respective schools. Interviewing multiple participants at two levels of leadership at each site provided a congruence of themes. Strengthening the trustworthiness of the findings. While the findings from this study cannot be generalized for all independent schools across Australia, the similarities between both schools, such as having a comparable range of socio-educational advantage, a larger proportion of the student population having English as their main language, and similar organizational structures, i.e. primary and secondary sections, shared some similarities with other schools across the Victorian independent sector where these findings might be relevant and transferable.

Case-study school 1 was an independent, single-sex school located in the inner eastern part of Victoria, with 173 employed teaching staff and 103 non-teaching staff. The school is multi-sited. It has 800 students enrolled with $82 \%$ native English speakers and 18\% non-native English speakers. The school has $88 \%$ of its parents in the upper $50 \%$ of socio-educational advantage. Case-study school 2 was an independent co-educational school located in the outer eastern part of Victoria, with 73 employed teaching staff 
and 52 non-teaching staff. The school is single-sited. It has 390 students enrolled with $77 \%$ native English speakers and 23\% non-native English speakers. The school has $68 \%$ of its parents located in the upper $50 \%$ of socio-educational advantage and $32 \%$ in the lower $50 \%$ of socio-educational advantage.

By using a constructivist approach, the researcher investigated the social construction around DIDM within these schools as the study sought to examine the "multiple realities associated with different groups and perspectives" (Maxwell, 2011, p. 10) around actual data use and data-informed practice. According to Ponelis (2015), using a case-study approach "is particularly appealing for applied disciplines since processes, problems, and programs can be studied to engender understanding that can improve practice" (p. 536). The researcher moved from a conventional to an alternative research approach engaging in deeper critical understandings around the practice of data use in schools. The researcher used different aspects of selfreflexivity during the study to uncover more nuanced understandings around data use as discussed below.

\section{Moving from conventional to alternative research methods - Researching data use practices}

Coburn and Turner (2012) discussed three unsuccessful conventional research approaches that have failed to highlight the issues around the "actual practice" of data use, which is relevant since data use remains underutilized and underresearched in Australian schools. First, a focus on aggregate outcomes and data use through school improvement initiatives undertaken by successful data use schools. Second, a focus on data-informed activities that schools engage in where emphasis is given to the data use interventions instead of the relational aspects involved within the practice of data use. Third, research that focuses on providing an optimistic approach to data use through "how-to guides" focusing on the importance of data use. These conventional research approaches do not provide insight into the educational processes through which outcomes are produced; into educational interventions developed and implemented; or into an alternative approach undertaken based on the identification of significant contextual realities that enable or disable the practices of data use.

Coburn and Turner (2012) suggested that research should pay attention to the practice of data use through deeper investigations into understandings around what actually happens when people engage with data during their ongoing everyday schoolwork and by making connections on how this engagement relates back to instructional change, where visible shifts are found in student achievement and organizational learning. Hence, instead of focusing on an optimistic approach to data use, preference in this study was given to a realistic approach, understanding how senior and middle-level 
school leadership engage in understanding their data, make better decisions based on inferences drawn from the data and shift their continuous school improvement processes in the right direction. Schildkamp et al. (2017) suggested how these realistic approaches could be enacted as "practice" within schools,

....in order for data-based decision-making to lead to school improvement in terms of increased student achievement, it is crucial that data are also used for school development and instructional purposes. Therefore, we need to study the extent to which school staff use data for accountability, school development, and instructional purposes (p. 243).

Research into these practices investigates what really happens when people at different levels within a school organization use external and internal data in their regular day-to-day practice. Conventional research approaches in Australian literature on DIDM have not discussed the reality around the kinds of data interactions and sense making that people engage in at the system or school level and how these interactions impact practice. These approaches have also not identified ways in which data is interpreted and embedded into the redesign of continuous school improvement activities. The challenges and tensions faced in these practices and how schools have overcome the challenges or have delayed using DIDM have not been sufficiently discussed. The context-specific impact analysis of data-informed interventions requires further research into why interventions might work well in one setting and yet fail to do so in another setting.

Maxwell (2012) discussed an alternative research approach that can be used to address this gap, known as "causal explanation." This provided the researcher with opportunities to better understand the contextual realities within which participants engaged or disengaged with DIDM processes and their use in their schools. In justifying this research approach within qualitative research studies like the current study, Maxwell (2012) further stated that:

This alternative approach to causation is compatible with the practice and "theory-in-use" of many qualitative researchers and enables qualitative researchers to credibly make and support causal claims... Adequate causal explanations in the social sciences depend on the in-depth understanding of meanings, contexts, and processes that qualitative research can provide (p. 655).

Likewise, Pawson (2006) asserted that "the nature of causality in social programs is such that any synthesis of evidence on whether they work will need to investigate how they work. This requires unearthing information on mechanisms, contexts, and outcomes" (p. 25). Findings from this Australian 
study investigated the practice of data use in schools by looking at relationships between school leaders, their theories-in-use, and their active engagement or passive disengagement with data as they engaged in sense-making of data within their respective school contexts.

\section{Exercising deeper researcher reflexivity - embedding four ways of reflective thinking} As this was a qualitative explorative study, the researcher was interested in studying how meanings around the practice of a data-informed approach to decision-making were developed especially within the particular social, cultural, and relational context of these case-study schools. Reflexivity is the process of examining oneself as a researcher; the research process and the research relationships develop between the researcher and the research participants. Guba and Lincoln (2005) defined reflexivity as "a conscious experiencing of the self as both inquirer and respondent, as teacher and learner, as the one coming to know the self within the processes of research itself" (p. 183).

The researcher had previously worked in both teaching and leadership roles in schools and used their own insider understanding of schools to recognize causal explanations of the practice of DIDM processes being observed. Mann (2016) discussed the importance of a reflective journal and suggested that

keeping a journal or diary is desirable if not essential in qualitative research... The journal is a vehicle to explore a dialogue between theory, experience, and identity. It helps make explicit, your assumptions and evaluate how this shapes the interview interaction (p. 19).

Mann (2016) explained how the journal provides space for "qualitative researchers to record dilemmas, concerns, and troubling ethical questions, as well as breakthroughs and realisations" (p. 19).

The researcher used journaling to observe the processes of DIDM by using their insider-outsider perspective to make causal explanations of data use at these schools. Blaxter et al. (2001) addressed the strong reflexive approach used through a research journal by discussing four levels of reflexivity covering different pieces of the research process as well as the construction of research knowledge. These include: observational notes used to describe events such as observations and interviews; methodological notes focusing on the actions and role of the researcher; theoretical notes used to describe the preliminary understandings from the data; and analytical memos used to bring together and draw inferences after reviewing all the datasets collected, the notes, the memos, and the theoretical literature, so that the researcher works toward synthesizing patterns and themes that are emerging from the data. 
The researcher used field notes throughout the interviews and school observations. Field observations led the researcher to reflect on the research relationships developed through this study; the researcher examined their relationship with the research participants, and how the relationship dynamics had an effect on the responses to interview questions. This reflexive approach helped the researcher in examining their assumptions and preconceptions and considering how these could affect research decisions, particularly the selection of research participants, research methods, research questions, and theoretical literature, as well as the overall construction of research knowledge.

The researcher used methodological notes when revising the interview questions after collecting data from the first case-study school. Through the use of semi-structured interview questions, the researcher worked at developing a context of interactive meaning-making between researcher and research participants. Observations of school improvement activities and analysis of organizational documents were useful data collection methods requiring the researcher to exercise reflexivity from the beginning of data collection. The interpretation of these qualitative datasets required the researcher to engage in regular reflection on different aspects of the research context for each school. In exercising reflexivity, the researcher made the research process itself a focus of inquiry by laying open their preconceptions of DIDM and its links with school improvement processes and ensuring that these preconceptions did not influence the findings from this study. The researcher journaled a series of methodological notes as data was collected across the two case-study schools. For example, during the data-collection stages at case-study school 1, the researcher found the term "data-driven" had negative connotations associated with it, with research participants mostly aligning the purpose of their interview with the accountability aspect of DIDM, rather than the improvement aspect. This repeated observation with participants made the researcher reconsider the term through their reflections in their methodological notes, and revise it to "data-informed" instead of "datadriven" decision making at case-study school 2 .

Theoretical notes helped the researcher focus on theoretical literature from a new lens looking at the nuanced meanings behind data-driven decision-making and DIDM in the field. The researcher was careful in how theoretical literature would be positioned and used during data analysis. In discussing the practice of data use in schools, Datnow (2017) suggested that “....educators play a critical role in shaping how and why data are used, what counts as data, and so on. DIDM is a more appropriate term for this practice, rather than data-driven decision-making, used most often in the field" (p. 11). The theoretical reflexivity exercised through theoretical notes subtly moved the focus of the data analysis from studying what data-driven decision-making is and the effects it has on school improvement processes to studying how a DIDM context affects school 
improvement processes. Schildkamp et al. (2019) described DIDM as a new way "in which data can never completely drive decisions. Instead, data can inform decisions, which, combined with the professional knowledge of educators, can contribute to achievement and learning in schools" (p. 2).

During data collection, the researcher used NVivo and Endnote software to analyze and develop analytical memos to synthesize emerging themes within the data. Reflexivity through analytical memos facilitated the researcher in making deeper connections between theory and data. They continued to reflect upon understanding how and why the practice of data use in decision making provided a more nuanced understanding to the role of evidence-based continuous school improvement practice. Through self-reflection, the researcher worked at ensuring that they had not assumed that meanings around this nuanced understanding of the practice of data use in decision making suggested that data use was fixed, static, stable, concrete, and ready for use in any school context. They found that analytical reflexivity allowed them to continue checking and establishing that they had not developed expectations that truth could be discovered by asking the right questions, made assumptions that their questions were always objective, or assumed that participant answers were straightforward, with clear and definitive meanings and singular realities. Instead, through on-going reflexivity and using a "causal explanation" research approach, the researcher worked at understanding how all meanings were interactively and culturally constructed and how each of these research participants as individual social actors were variously located within the social settings at their respective schools. The researcher sought to understand the positioning of leaders at each of these research sites by observing the way they were positioned by their leadership position, subject expertise, gender, age and other emerging ascriptive characteristics that came through the data. This reflexivity helped the researcher to move beyond the apparent and to better understand what was obscure in the processes being examined. A cross-comparative thematic analysis was used while analyzing data from which two main themes emerged.

\section{Findings}

First, the findings brought to light patterns of disengaged versus engaged DIDM practices found at these schools and their effect on the continuous school improvement processes. This finding directly informed the researcher of the influence that an enhancement of school system capabilities has when DIDM processes are applied. Second, the findings indicated that when looking at the role and actual involvement of senior and middle-level school leaders and their influence on a data-informed school culture, various kinds of active 
and passive forms of leadership dispositions emerged. The findings also suggested that the importance of contextual realities within independent schools should be considered in discussions around DIDM processes since these schools operate as independent, autonomous entities led by school leadership teams and school councils.

\section{Enhancing school system capabilities:}

Dynamic versus passive engagement in data-informed decision-making processes The findings from the two schools explored how school personnel engaged with data during the course of their ongoing everyday work and made decisions that affected the organizational culture within these schools. The data analysis focused on investigating their ways of thinking around data use, their use of school-based data management systems, their leadership practices, and their system supports that some of the organizational processes used for enhancing school system capabilities.

In both cases, school datasets were used conservatively, with school leaders and teachers unable to see the scope of using data for deeper analysis on their school practice. School leaders engaged with data in two significant ways that impacted how decision-making processes around school improvement took place. These approaches included either active, mindful collection of data for school improvement or more traditional collection of data for the purpose of recording and archiving information. The former approach was progressive and dynamic; the latter was passive and limited. The findings indicated that while huge amounts of data were collected, not all of it was actively used. As one senior leader noted,

One of our strengths I think is that we have lots of data, we actually are almost like drowning in data, we collect a lot of different data, whether it's questionnaires or making observations. We have a supportive principal who is really interested in data, we have some staff with experience, we have also got some interested staff, so they may not have experience, but they're interested. But there is not much use of this data except for some datasets and those are used mostly for the reason why they were collected [CSS 1.1].

As indicated, the purpose of data collection was not always clear, nor was it always easy to know the link between the collection of data and its influence within their current school improvement agenda. At times, an absence of policies around the purpose of data collection led to datasets being collected but having no direct influence on school improvement processes. As this leader noted:

One of our weaknesses is that we actually don't have enough data-literate people on staff. There are only a few systems for using data in place, we've talked about that at times, but feedback. cycles are either minimal or not structured enough to make better use of the data [CSS 1.1]. 
This indicated that the wider usage of data was restricted by a limited understanding of the interpretation of quantitative datasets, a lack of analytical expertise in the practice of data use for school evaluation, and a lack of expertise in the analysis and inferencing of multiple datasets. This suggested that data use did not include a data-informed approach with analytical interconnections drawn amongst school improvement elements. One or two expert data-literate or data-numerate staff members were on staff and were called upon to use their data interpretation skills. A lack of proper data use or re-use of previously analyzed datasets for trend-mapping was found. As a middlelevel leader from case-study school 2 mentioned:

We used to get the VCE [Victorian Certificate Exam] data - we did have access to the printouts, but no-one really walked us through and explained how they worked, because there's a lot of scaling and different things. And if you didn't have that background knowledge, it was difficult. So, one of the teachers in the science department, this is something be really enjoys, and so be will sit down with you one-on-one or in a meeting style and run through with you how to best utilize that data. And since that has happened in the last three years, it has been really beneficial. I can really understand the data. I get where I could have done better, or actually, where I'm doing really well, and how I can support my next lot of Year 12 students, the next year [CSS2.2].

Due to this lack of analytical understanding around data use, there was an avoidance by participants around its use in active decision-making processes; the approach for data use was ad hoc, with school leaders preferring to rely on their own professional judgment and experience or that of their peers to make decisions, even though they had school datasets.

\section{Role of leadership: Proactive versus inactive involvement}

In this study, two main types of leadership dispositions towards DIDM were identified. School leaders at both levels either proactively used DIDM or avoided the use of data and played down its importance within school improvement processes, demonstrating clear inactive involvement.

At case-study school 1, a new sophisticated data management system was put in place at the start of the school year with very little time and information given to leaders at either level to help understand how they would use this system to streamline the school improvement processes they were to lead. This weak change approach resulted in limited engagement with datasets available through the data management system and disengaged decisionmaking processes occurring as the school underwent a problematic roll-out of this change process. A number of senior and middle-level school leaders were not professionally developed in the necessary technological skills required for this change to occur smoothly. Some leaders were not kept fully 
informed within the communication loop on key decisions regarding continuous online student reporting, curriculum management and student welfare systems integrated within this data management system. The findings indicated a need for stronger relationships around data use developed between senior and middle-level leaders and between middle-level leaders and teachers at these schools. One of the leaders stated:

I think that even having the sort of understanding that we've got data and having a group of people get together to look at the data is a new idea. While there's some privacy issues around some datasets, we've talked about de-identifying that. However, everyone sits on their data and doesn't want to discuss it together. At [CSS1], it's very much like that. Even the idea of people talking to each other about this is a bit new. It hasn't happened yet... that's part of the cultural thing - that we've worked in silos for so long and they've not really been asked to do that [CSS1.14].

A transformational leadership approach across both levels of leadership was noticeably absent or only developing. Such an approach would facilitate building a stronger organizational culture for school improvement. The findings suggested that developing stronger organizational trust through transparent systems of planning, organizing, and monitoring could have assisted in better integration of DIDM. Also, the strengthening of communication channels between both levels of leadership was critical. As one of the leaders suggested:

I guess what I would love to see is that we take this opportunity to say what could we do better as a professional learning community? Let's set up time for teams to work together, because with that we're going to be achieving so much. It'll be about the learning, and the learning management system] will be part of that. It will be about what data do we have that shows us, you know, what interventions are required? What's tracking along really well? And then from there, okay, how will [the learning management system] help us with that? I think that brings the focus back. to "Well we're here as a community, we're here for our learning and teacbing, we see that as a priority and we're going to provide time for that" [CSS 1.7].

As seen in the above quote, as with any change improvement, people need to have the necessary skills required for the assigned improvement task and time assigned to study how best to implement the change, to make the change, and then to reflect and improve upon the change.

At case-study school 2, senior leaders expressed concern about the insufficient time for reflection on the enactment of data-informed continuous school improvements. The busyness of schools kept them from having more mindful time for using data effectively. This was mostly attributed to a feeling of "change-weariness" within these schools. As a senior leader discussed: 
Schools are very busy places. I see too often things being implemented in schools that start, but never finish. And part of that reason is because something else comes along that is either more important or more urgent... I think the key to any professional development in a school environment is allowing teachers to own their areas of teaching and learning and for the data to enhance what they are doing. Developing this skill is important for all teaching staff in the school before we start using data in all our decisions... [CSS2.4].

As this leader went on to discuss, while there were a number of datasets available for school leaders to access and use through highly sophisticated data management systems and the supports that were being provided, senior school leaders did not always make clear connections between what the data was indicating and how they could then lead others in putting evidence-based improvements into practice. In their words:

Because within our own school system, we have a data person who will give us data on financials, on NAPLAN, on school surveys that we are asked to do. But who will give us data on other teaching and learning areas? So as a senior-level school leader, I sit there and go, "Great, this is fantastic information, but how do we then follow up to build the school culture and what support do we have in place for that?" I don't want us misinterpreting datasets because of our busyness. Because there's always something that gets in the way. It's either something else or it's more important or it's an emergency that comes in. So, I'm all for building professional learning environments within schools, but I'm not for something new coming in all the time, on a regular basis. With the data that comes in throughout the year we need to know when and how to use it effectively. At the moment, we don't know how to do it [CSS2.4].

As indicated above, a sense of busyness resulting in a fear of data misuse leading to incorrect interpretations and decisions makes school leaders steer away from using datasets even though these datasets could provide clear insight on their organizational climate as well as their teaching and learning processes. This fear of data misuse directly fed into reducing the organizational trust relationships within senior leaders and amongst senior and middle-level leaders, leading to a trickle-down effect of less organizational trust between middle-level leaders and their teachers. These low levels of trust were indicated through what the researcher identified as data fortresses built by school leaders where significant restrictions were placed around data accessibility, so that data was accessible only to a few leaders. Factors contributing to the existence of these data fortresses included an imbalance of leadership influence, a lack of horizontal and vertical organizational communication, and less collaboration amongst staff even though sophisticated data management systems had been installed at this school. A lower level of organizational trust being exercised by senior and middle-level leaders toward widespread data use led directly to a passive disengagement of teaching staff from DIDM practices. 


\section{Discussion}

Due to the autonomous nature of independent schools (ISCA, 2018), the findings from these two case-study schools indicated that the principals, school boards, and leadership teams needed to work together consistently within their main decision-making processes when considering the complexities and challenges of their schools. However, as suggested by Independent Schools Queensland (ISQ, 2017), along with their autonomy as independent schools, "collaboration" within these schools was essential, since:

Autonomy alone is no guarantee of good performance, and if the capacity for decision-making is not carefully tailored to the environment, and the needs of students, there is little gain over a highly-centralised system... The impact of school autonomy on performance is enhanced when there is a culture of collaboration between teachers and school leaders in managing a school. This is the "glue" for what makes autonomy work in terms of smart use of resources and intelligent accountability. It involves collaboration at all levels (p. 5).

At both schools, it was found that building a data-informed school culture was necessary before DIDM could be used as a continuous school improvement practice. The findings suggested that data was often used or reviewed simplistically for the purpose it was mainly collected for. This approach lacked the provision of opportunities for deeper analysis and data engagement by these schools. The use of datasets for multiple purposes or for mapping trends around cohorts, grades, or subjects was limited. Similarly, the data management systems had limited access to datasets, providing those with access to positional power over others. These leaders were limited by their own competency and propensity toward the use of data. An efficacy toward the use of data for reflection and continuous school improvement was found limited to a few aspects of school management and administration at both schools.

There was a need for leaders and teachers at each school to feel supported while developing professional learning environments where DIDM was consistently used (Schildkamp et al., 2019; Van Gasse et al., 2016; Vanlommel et al., 2016). It was found that having a strong school culture with organizational trust was essential for promoting DIDM (Fernandes, 2021), as this broke down the need for data fortresses. Holmes et al. (2013) found that the ability to build trust relationships within their schools was one of five main characteristics of effective school leaders. Holmes et al. (2013, p. 276) suggested that "the building of social cohesion and trust is a key factor in ensuring that staff are committed to working toward shared goals and ongoing effort is required to maintain these relationships over time." 
In looking for causal explanations around the passive or limited data use evidenced at both schools, Marsh et al. (2006) suggested that

... equal attention needs to be paid to analyzing data and taking-action based on data. These are two different steps: taking-action is often more challenging and might require more creativity than analysis. Yet, to date, taking-action generally receives less attention, particularly in the professional development provided to educators. School staff often lack not only the data analysis skills (e.g., knowledge of how to interpret test results), but also guidance in identifying solutions and next steps in addressing diagnosed problems (p. 10).

The findings indicated that while these schools provided substantial allocation of resources for data collection and had sophisticated data management systems, more work was needed on developing the data competence of leaders and teachers so that DIDM could be integrated into regular school improvement processes. The disengagement observed at these schools was due to a lack of emphasis given to building DIDM into the school organizational culture (Schildkamp et al., 2019; Van Gasse et al., 2016; Vanlommel et al., 2016).

Four levels of engagement in data use were found at these schools, with not all leaders ascribing to any single level but rather demonstrating variance in the level of organizational capability. This engagement directly affected how data were used and was directly influenced by senior and middle-level leadership. At Level One - Data Avoidance, the findings indicated that school leaders distrusted data and avoided using it actively or proactively when managing or leading those working with them. The use of data was very limited in such instances and was restricted to just "a chosen few" within the school system. At Level Two - Data Indifference, the findings indicated that school leaders took note of trends in datasets but did not proactively work at improving the system based on evidence from these datasets. The data was sometimes reported to others; when used to inform a limited number of decision-making processes within the school, it was mostly in line with the obvious purpose of data collection. At Level Three - Data-Based, the findings indicated that school leaders used data more proactively but only when it supported their own opinions and decisions and as a means of justification. This instrumentalist approach to data use was found amongst leaders especially when they wanted to inform their teams of decisions that were top-down in their approach. The data use in such cases was still limited as the focus was on confirming for the teaching staff and with the teaching staff the need for mandated change. This did not allow staff to interrogate the data and to establish new ways of thinking and decision making. Finally, at Level Four - Data-Informed, the findings indicated that when these school leaders used the datasets to shape and inform their decisions for school improvement, they confidently used the datasets on a regular basis and for 
multiple purposes being both data literate and numerate. At this stage, DIDM was firmly embedded within their leadership disposition and practice and its usage then filtered down into proactive data teams at these schools. These four levels of engagement provide insight into how these schools may continue to work at building up the capabilities of their leaders as well as organizational decision-making processes so that this variance across four levels of data use can be decreased over time. Both schools had installed advanced data management systems. However, a lack of strong transformational leadership in data use hindered these schools in having more active use of data within their school improvement approaches. The findings suggest that more work at each of these schools in building up communities of practice where their respective data teams play an active role could be transformational in their continuous school improvement processes.

\section{Conclusion}

The findings from this small-scale research study suggest that DIDM can be improved within these schools as they work at enhancing their own system capabilities so that dynamic engagement with DIDM processes is embedded in their school improvement processes (Datnow et al., 2017; Schildkamp et al., 2017; Vanlommel et al., 2018). The findings also suggest that both senior and middle-level school leaders at these schools required the right kind of transformational leadership approach and data expertise to lead a dynamic engagement of data use within their schools. These school leaders needed better understanding of datasets and of the functionality of their datamanagement systems (Fernandes \& Henderson, 2020) to further embed this evidence-based approach to organizational change and development (Fernandes, 2019). As found within this study, data-informed school leaders can in effect build organizational trust through development of collaborative school improvement spaces where DIDM is part of the collective thinking and working psyche of the school.

While at national and state levels there is mandated accountability for school improvement due to the high cost of education to the nation, it would seem that autonomous schools in the independent sector need to give serious consideration to these new forms of evidence-based and data-informed accountabilities and the growing influence they have on the regular practice of school improvement within their respective schools. The exploratory results of this small-scale study provide insight into how a case could be made for similar independent schools to work on embedding the regular practice of DIDM within their school improvement processes. Through collaborative decision-making processes using datasets, these case-study schools could 
work at diagnosing, repairing, and improving themselves. Through further use of DIDM, these case-study schools could work to develop effective internal accountability measures that assist them in developing consistency in their school improvement processes, especially as they address some of the external pressures that independent Australian schools are facing today.

This current study recommends further research investigating how organizational trust processes can be developed by school leaders in Australian independent schools through DIDM practices, especially within active communities of practice. Another area for further research would be looking into how effective systems around data-access may contribute toward better communication and collaboration at senior and middle-level school leadership.

\section{Funding Acknowledgement}

This project was funded under the Dean's Early Career Research Project Award from Monash University, Australia, in the amount of AUD \$30,336 over 2017-2018.

\section{References}

Argyris, C., \& Schön, D. A. (1996). Organizational learning II: Theory, method andpractice. Addison-Wesley. Bernhardt, V. L. (2003). No schools left behind. Educational Leadership, 60(5), 26-30.

Blaxter, L., Hughes, C., \& Tight, M. (2001). How to research? (2nd Ed.). Open University Press.

Brown, C. (2015). Conclusion. In C. Brown (Ed.), Leading the use of research and evidence in schools (pp. 153-160). Institute of Education Press.

Coburn, C. E., \& Turner, E. O. (2012). The practice of data use: An introduction. American Journal of Education, 118(2), 99-111. https://doi.org/10.1086/663272

Cook, S. D. N., \& Brown, J. S. (1999). Bridging epistemologies: The generative dance between organizational knowledge and organizational knowing. Organization Science, 10(4), 381-400. https://doi.org/10.1287/orsc.10.4.381

Datnow, A. (2017, August). Opening or closing doors for students? Equity and data-driven decision-making [conference paper]. ACER Research Conference 2017, Australia. http://research.acer.edu. au $/$ cgi $/$ viewcontent.cgi?article $=1317 \&$ context $=$ research_conference

Datnow, A., Greene, J. C., \& Gannon-Slater, N. (2017). Data use for equity: Implications for teaching, leadership, and policy. Journal of Educational Administration, 55(4), 354-360. https:// doi.org/10.1108/JEA-04-2017-0040

Datnow, A., \& Hubbard, L. (2015). Teachers' use of assessment data to inform instruction: Lessons from the past and prospects for the future. Teachers College Record, 117(4), 1-26. https:// doi.org/10.1177/016146811511700408

Datnow, A., \& Hubbard, L. (2016). Teacher capacity for and beliefs about data-driven decisionmaking: A literature review of international research. Journal of Educational Change, 17(1), 7-28. https://doi.org/10.1007/s10833-015-9264-2 
Datnow, A., \& Park, V. (2018). Opening or closing doors for students? Equity and data use in schools. Journal of Educational Change, 19(2), 131-152. https://doi.org/10.1007/s10833-0189323-6

Earl, L. M., \& Katz, S. (2006). Leading schools in a data-rich world: Harnessing data for school improvement. Corwin.

Earl, L. M., \& Timperley H. (2009). "Understanding how evidence and learning conversations work.” In L. M. Earl \& H. Timperley (Eds.), Professional learning conversations: Challenges in using evidence for improvement (pp. 1-12). Springer. https://doi.org/10.1007/978-1-4020-6917-8_1

Fernandes, V. (2016). Reframing continuous school improvement in Australian schools. In A. Normore, L. Long, \& M. Javidi (Eds.), Handbook of research on effective communication, leadership, and conflict resolution (pp. 98-124). IGI Global. http://doi.org/10.4018/978-1-4666-9970-0.ch006

Fernandes, V. (2019). Investigating the role of data-driven decision-making within school improvement processes. In R. Hamlin, A. Ellinger, \& J. Jones (Eds.), Evidence-based initiatives for organizational change and development (pp. 201-219). IGI Global. http://doi.org/10.4018/9781-5225-6155-2.ch010

Fernandes, V. (2021). Making sense of data-informed decision making in educational contexts. In M. Khosrow-Pour (Ed.), Handbook of research on modern educational technologies, applications, and management (pp. 545-563). IGI Global. http://doi.org/10.4018/978-1-7998-3476-2.ch033

Fernandes, V., \& Henderson, M. (2020). Activating turnaround leadership solicitation of datainformed decision-making within Australian public schools. In C. V. Meyers \& M. J. Darwin (Eds.), School turnaround in secondary schools: Possibilities, complexities, and sustainability (1st Ed.), (pp. 59-81). Information Age Publishing.

Guba, E. G., \& Lincoln, Y. S. (2005). Paradigmatic controversies, contradictions, and emerging confluences. In N. K. Denzin \& Y. S. Lincoln (Eds.), The Sage bandbook of qualitative research (3rd Ed.) (pp. 191-215). Sage.

Hansen, J. M., Gentry, R., \& Dalley, T. (2003). Mindful change in a data-driven school. Principal Leadership, 3(6), 37-41.

Harris, A., \& Hargreaves, A. (2015). Exceptional effectiveness: Taking a comparative perspective on educational performance. International Congress for School Effectiveness and School Improvement, $8,7-40$.

Harris, A., \& Jones, M. (2017). Leading in context: Putting international comparisons into perspective. School Leadership \& Management, 37(5), 431-433. https://doi.org/10.1080/136324 34.2017.1368864

Holmes, K., Clement, J., \& Albright, J. (2013). The complex task of leading educational change in schools. School Leadership \& Management, 33(3), 270-283. https://doi.org/10.1080/136324 34.2013.800477

Honig, M. I., \& Coburn, C. E. (2008). Evidence-based decision making in school district central offices. Educational Policy, 22(4), 578-608. https://doi.org/10.1177/0895904807307067

Independent Schools Council of Australia (ISCA). (2018). Independent Schooling in AustraliaSnapshot 2018. ISCA. http://isca.edu.au/wp-content/uploads/2018/05/18189-ISCA-2018Snapshot-A4-2pp.pdf

Independent Schools Queensland (ISQ). (2018). Independent Schools are more accountable than ever. Briefings: Thought leadership for the independent schooling sector, 22(2), 1-8.

Independent Schools Queensland (ISQ). (2017, May). Autonomy and school leadership: An independent schooling perspective [Discussion paper]. Independent Schools Queensland. 
Lai M., \& Schildkamp, K. (2013). Data-based decision making: An overview. In K. Schildkamp, M. Lai, \& L. Earl (Eds.), Data-based decision making in education. Studies in educational leadership (pp. 9-21). Springer. https://doi.org/10.1007/978-94-007-4816-3_2

Lai, M. K., Wilson, A., McNaughton, S., \& Hsiao, S. (2014). Improving achievement in secondary schools: Impact of a literacy project on reading comprehension and secondary schools' qualifications. Reading Research Quarterly, 49(3), 305-334. https://doi.org/10.1002/rrq.73

Lincoln, S. Y., \& Guba, E. G. (1985). Naturalistic inquiry. Sage.

Mandinach, E. B., \& Gummer, E. S. (2013). A systemic view of implementing data literacy in educator preparation. Educational Researcher, 42(1), 30-37. https://doi.org/10.3102/ 0013189X12459803

Mandinach, E. B., Parton, B. M., Gummer, E. S., \& Anderson, R. (2015). Ethical and appropriate data use requires data literacy. Phi Delta Kappan, 96(5), 25-28. https://doi.org/10.1177/ 0031721715569465

Mann, S. (2016). The research interview: Reflective practice and reflexivity in research processes. PalgraveMacmillan. https://doi.org/10.1057/9781137353368

Marsh, J. A., Pane, J. F., \& Hamilton, L. S. (2006). Making sense of data-driven decision making in education: Evidence from Recent RAND Research (OP-170). RAND Corporation. https://doi. org/10.7249/OP170

Maxwell, J. A. (2011). Epistemological heuristics for qualitative research. In H. Soini, E. L. Kronqvist, \& G. L. Huber (Eds.), Epistemological heuristics for qualitative research (pp. 10-27). Center for Qualitative Psychology.

Means, B., Padilla, C., DeBarger, A., \& Bakia, M. (2009). Implementing data-informed decision making in schools-Teacher access, supports and use. Report prepared for U.S. Department of Education, Office of Planning, Evaluation and Policy Development. SRI International. https://files.eric. ed.gov/fulltext/ED504191.pdf

Park, V., \& Datnow, A. (2009). Co-constructing distributed leadership: district and school connections in data-driven decision-making, School Leadership \& Management: Formerly School Organisation, 29(5), 477-494. https://doi.org/10.1080/13632430903162541

Pawson, R. (2006). Evidence-based policy: A realist perspective. SAGE.

Phillips, J. (2003). Powerful learning: Creating learning communities in urban school reform. Journal of Curriculum and Supervision, 18(3), 240-258.

Ponelis, S. R. (2015). Using interpretive qualitative case studies for exploratory research in doctoral studies: A case of Information Systems research in small and medium enterprises. International Journal of Doctoral Studies, 10, 535-550.

Poortman, C. L., \& Schildkamp, K. (2016). Solving student achievement problems with a data use intervention for teachers. Teaching and Teacher Education, 60, 425-433. https://doi. org/10.1016/j.tate.2016.06.010

Robinson, V. M. J., \& Walker J. C. (1999). Theoretical privilege and researchers' contribution to educational change. In J. S. Gaffney \& B. J. Askew (Eds.), Stirring the waters: The influence of Marie Clay (pp. 239-259). Heinemann.

Schildkamp, K., \& Kuiper, W. (2010). Data-informed curriculum reform: Which data, what purposes, and promoting and hindering factors. Teaching and Teacher Education, 26(3), 482-496. https://doi.org/10.1016/j.tate.2009.06.007

Schildkamp, K., \& Lai, M. K. (2013). Conclusions and a data use framework. In K. Schildkamp, M. K. Lai., \& L. Earl (Eds.), Data-based decision making in education: Challenges and opportunities (pp. 177-191). Springer. https://doi.org/10.1007/978-94-007-4816-3_10 
Schildkamp, K., Poortman, C., Luyten, H., \& Ebbeler, J. (2017). Factors promoting and hindering data-based decision making in schools. School Effectiveness and School Improvement, 28(2), 242-258. https://doi.org/10.1080/09243453.2016.1256901

Schildkamp, K., Poortman, C. L., Ebbeler, J., \& Pieters, J. M. (2019). How school leaders can build effective data teams: Five building blocks for a new wave of data-informed decisionmaking. Journal of Educational Change, 20(3), 1-43. https://doi.org/10.1007/s10833-019-09345-3

Smeed, J. L., Ehrich, L. C., Kimber, M., \& Perry, L. (2011). Data-driven accountability in Australia: An unfolding story with lessons for leaders. The Australian Educational Leader, 33(2), $17-20$.

Spillane, J. P. (2012). Data in practice: Conceptualizing the data-based decision-making phenomena. American Journal of Education, 118(2), 113-141. https://doi.org/10.1086/663283

Thoonen, E. E. J., Sleegers, P. J. C., Oort, F. J., Peetsma, T. T. D., \& Geijsel, F. P. (2011). How to improve teaching practices: The role of teacher motivation, organizational factors and leadership practices. Educational Administration Quarterly, 47(3), 496-536. https://doi. org/10.1177/0013161X11400185

Timperley, H. S. (2005a). Distributed leadership: Developing theory from practice. Journal of Curriculum Studies, 37(4), 395-420. https://doi.org/10.1080/00220270500038545

Timperley, H. S. (2005b). Instructional leadership challenges: The case of using student achievement information for instructional improvement. Leadership and Policy in Schools, 4(1), 3-22. https://doi.org/10.1080/15700760590924591

Timperley, H. S. (2006). Learning challenges involved in developing leading for learning. Educational Management Administration and Leadership, 34(4), 549-566. https://doi.org/10.1177/ 1741143206068217

Van Gasse, R., Vanlommel, K., Vanhoof, J., \& Van Petegem, P. (2016). Teacher collaboration on the use of pupil learning outcome data: A rich environment for professional learning? Teaching and Teacher Education, 60, 387-397. https://doi.org/10.1016/j.tate.2016.07.004

Vanhoof, J., Verhaeghe, G., Van Petegem, P., \& Valcke, M. (2012). Flemish primary teachers' use of school performance feedback and the relationship with school characteristics. Educational Research, 54(4), 431-449. https://doi.org/10.1080/00131881.2012.734726

Vanlommel, K., Vanhoof, J., \& Van Petegem, P. (2016). Data use by teachers: The impact of motivation, decision-making style, supportive relationships and reflective capacity. Educational Studies, 42(1), 36-53. https://doi.org/10.1080/03055698.2016.1148582

Vanlommel, K., Van Gasse, R., Vanhoof, J., \& Van Petegem, P. (2018). Teachers' high-stakes decision making. How teaching approaches affect rational and intuitive data collection. Teaching and Teacher Education, 71, 108-119. https://doi.org/10.1016/j.tate.2017.12.011

Wayman, J. C., \& Jimerson, J. B. (2014). Teacher needs for data-related professional learning. Studies in Educational Evaluation, 42, 25-34. https://doi.org/10.1016/j.stueduc.2013.11.001

Wayman, J. C., Jimerson, J. B., \& Cho, V. (2012). Organizational considerations in establishing the Data-Informed District. School Effectiveness and School Improvement, 23(2), 159-178. https:// doi.org/10.1080/09243453.2011.652124

\section{Corresponding author}

Venesser Fernandes

Faculty of Education, Monash University, Melbourne, Australia

E-mail: venesser.fernandes@monash.edu 